\title{
Solitary neurofibroma of the gingiva with prominent differentiation of Meissner bodies: a case report
}

\author{
Jun Ohno*, Teruaki Iwahashi, Ryuki Ozasa, Kazuhiko Okamura, Kunihisa Taniguchi
}

\begin{abstract}
Background: Oral neurofibromas are peripheral nerve sheath tumors, similar to schwannomas. Histological variations in oral neurofibromas are relatively uncommon.

Case presentation: Here, we present a case of unique variation in the observed characteristics of a neurofibroma, with no relation to neurofibromatosis type-1 or von Recklinghausen disease of the skin. The neurofibroma was observed in the right mandibular gingiva of a 32-year-old Japanese woman. Histologically, it differed from conventional neurofibromas in that the tumor was composed of a mixture of fine fibrillary collagen in sheets and/ or cords of neoplastic Schwann cells containing numerous clusters of Meissner bodies. Histologically, these bodies were in contact with neoplastic Schwann cells. The Meissner bodies were immunopositive for S-100 protein, neuron-specific enolase, and vimentin, but were negative for calretinin. CD34-positive spindle cells were observed around the Meissner bodies. No recurrence or signs of other tumors have been observed in the patient for 5 years after tumor resection.

Conclusion: To the best of our knowledge, no formal descriptions of sporadic, solitary neurofibromas containing numerous Meissner bodies occurring in the oral cavity are available in literature. We believe that an uncommon proliferation of Meissner bodies, as seen in the present case, may result from aberrant differentiation of neoplastic Schwann cells.
\end{abstract}

\section{Background}

Neurofibromas are benign tumors showing neural differentiation and they originate from the sympathetic, peripheral, or cranial nerves. The tumor typically presents either as a localized lesion or as part of a generalized syndrome of neurofibromatosis generally known as neurofibromatosis type-1 (NF1) or von Recklinghausen disease of the skin. NF1 is an inherited, autosomal dominant disorder characterized by multiple neurofibromas. Localized (solitary) neurofibromas most often occur as sporadic lesions in patients without NF1. In general, sporadic neurofibromas are histologically identical to those seen in NF1 [1]. They are clinically characterized by slow growth, lack of pain, and a superficial location. Histologically, these tumors are unencapsulated and comprise a mixture of Schwann cells, perineurial

\footnotetext{
* Correspondence: johno@college.fdcnet.ac.jp

Department of Morphological Biology, Division of Pathology, Fukuoka Dental College, Fukuoka, Japan
}

cells, and endoneurial fibroblasts [2-4], and are classified into major and minor variants based on their morphological features. Major variants include plexiform, diffuse, and pacinian neurofibromas, while minor variants include epithelioid, cellular, myxoid, glandular, xanthomatized, and other neurofibromas [5-7].

Although neurofibromas may often occur in the cervicofacial region, intraoral neurofibromas not related to NF-1 are relatively uncommon [8-10]. Except for plexiform and pacinian neurofibromas, limited information is available on the histological variants of oral neurofibromas. Here, we present a case of oral neurofibroma containing numerous clusters of Meissner bodies, which presented in the right mandibular gingiva of a 32-yearold Japanese woman.

\section{Case presentation}

A 32-year-old Japanese woman was referred to the Oral Surgery Clinic at the Fukuoka Dental College Hospital in 
Fukuoka, Japan for a painless swelling on the right mandibular gingiva. She did not have a family history of neurofibromatosis and had been aware of the lesion for approximately 8 years. Intraoral examination confirmed the presence of a pendunculated swelling on the posterior mandibular facial gingiva, which was located between the first and second molars (Fig. 1a). The excised specimen measured $2.0 \times 1.0 \times 0.8 \mathrm{~cm}$, appeared yellowishwhite in color, was relatively circumscribed but unencapsulated, and showed no evidence of hemorrhage or necrosis (Fig. 1b). Detailed examination of the patient revealed no evidence of café-au-lait spots, extraperineal cutaneous neurofibromas, or other stigmata associated with von Recklinghausen disease. After tumor excision, the patient has been on regular follow-up and has shown no recurrence or complications over the last 5 years.

Histologically, the lesion was found to be unencapsulated and showed diffuse, circumferential infiltration of the periosteal connective tissue surrounding the neurofibroma and was surfaced with stratified squamous epithelium. The tumor was composed of paucicellular



and cell-rich areas (Fig. 2a). The paucicellular areas were composed of a uniform fine fibrillary collagen matrix containing either a few spindle-shaped fibroblasts or mast cells (Fig. 2b). Prominent vascular channels were noted in these areas. The cell-rich areas displayed sheet- or cord-like growth patterns of tumor cells that had either short fusiform or rounded shapes (Fig. 2c). These cells, although histologically identical to Schwann cells, showed no evidence of cytological atypia or mitotic figures. Numerous pale eosinophilic globules containing parallel slits were observed within the cellular sheets. The globules were composed of narrow elongated cells stacked in a lamellar arrangement, and were histologically identical to the tactile corpuscle-like Meissner bodies (Fig. 2c and 2d). The nuclei of the laminar cells were located at the periphery of the corpuscles or were arranged transverse to their long axes, along the lamellae. Histologically, the Meissner bodies were in contact with the neoplastic Schwann cells. To determine the immunohistochemical characteristics of the Meissner bodies observed in the tumor, immunoperoxidase staining of the specimen was performed using the Histofine Simple Stain Kit (Nichirei, Tokyo, Japan), and the reaction products were visualized following exposure to diaminobenzidine. Antibodies to S-100 protein, calretinin, vimentin, neuron-specific enolase (NSE), and Ki-67 (MIB-1) were obtained from DakoCytomation (Kyoto, Japan). Anti-CD34 antibody was purchased from Nichirei (Tokyo, Japan). Modified microwave antigen retrieval in citrate buffer ( $\mathrm{pH}$ 6.0) was used for analyzing antibodies to calretinin, CD34, and Ki-67. The lamellar structures of the Meissner bodies were intensely immunoreactive to both S-100 protein and NSE (Fig. 3a and 3b). The Schwann cells observed in the cellular sheets reacted to both antibodies. A few single cells in the fibrous component were stained with S-100 protein or NSE. The Meissner bodies reacted positively to vimentin but to a lesser degree compared to that for S-100 protein or NSE (Fig. 3c). CD34-positive spindle cells were found around the Meissner bodies in the cellular sheets as well as in the clusters of Meissner bodies (Fig. 3d). The vascular endothelium of the fibrous component was also positive for CD34. All cells of the fibrous and cellular components were non-reactive to the other antibodies. Small clusters of S-100 protein-positive Meissner bodies were diffusely scattered throughout the periosteum (Fig. 4). In addition, immunostaining with the nuclear proliferation marker Ki-67 (MIB-1) revealed approximately $1 \%$ positivity in the tumor cells.

\section{Discussion}

Oral neurofibromas, like schwannoma are peripheral nerve sheath tumors. The characteristics encountered in the present case are identical to those of localized 


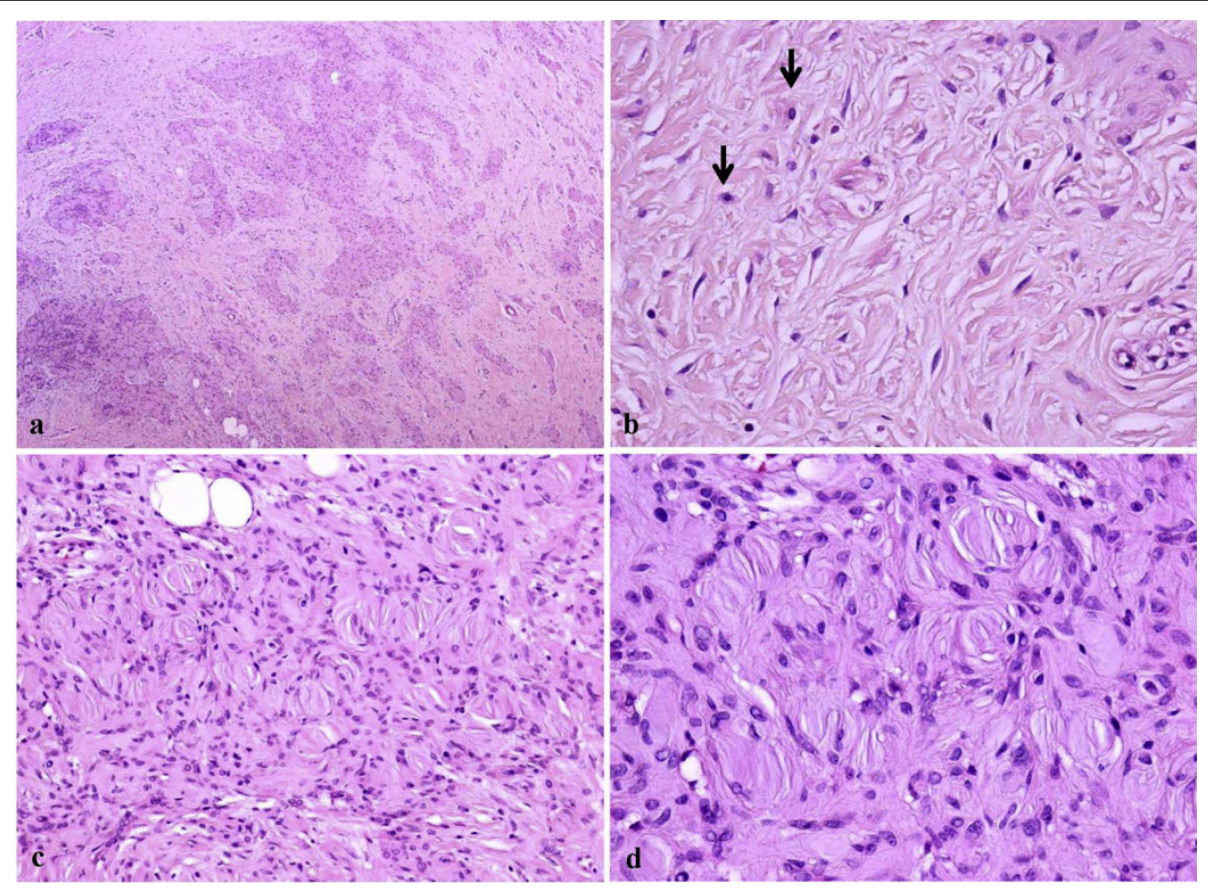

Figure 2 Microscopic findings of the tumor. (a) Fibrous and cellular components of the tumor. (b) Fibrous component of the tumor. Spindleshaped fibroblasts and mast cells (arrows) are scattered within the fibrous connective tissue. (c) Cellular sheet of the tumor. The sheet is composed of numerous Schwann cells and Meissner bodies. (d) High magnification of the Meissner bodies. Note the lamellar structures in these bodies. (hematoxylin and eosin staining; original magnifications: a, 100 x; b \& c, 200 x; d, 400 x).

(solitary) neurofibromas not related to NF1. Furthermore, the clinical findings and Ki-67 (MIB-1) labeling index in the present case observed are similar to those of conventional neurofibromas that are often diagnosed late because they tend to grow slowly as painless nodules that produce few symptoms. In the present case, the tumor was believed to have originated from a branch of the fifth cranial nerve, similar to that seen in other cases of intraoral neurofibromas [11]. However, the present case presented with a histology that differed from conventional neurofibromas in several respects: (1) the tumor was clearly composed of paucicellular and cell-rich areas, (2) the paucicellular areas comprised a uniform matrix of fine fibrillary collagen, (3) the neoplastic Schwann cells were less elongated than those encountered in conventional neurofibromas and showed either short fusiform or rounded contours, and (4) scattered clusters of Meissner bodies were present throughout the tumor.

The most prominent finding was the scattered presence of Meissner body clusters throughout the tumor. Meissner bodies are sensitive, tactile receptors concentrated in the dermal papillae of the digital tips, palms, and soles. Similar to their location in the skin, Meissner bodies are present at the apex of the gingival connective tissue papillae within the oral mucosa and function primarily as sensitive receptors for touch stimuli [12].
Histologically, Meissner bodies are not uncommon in conventional neurofibromas $[1,13,14]$. However, the histological characteristics observed in the present case differed from those seen in conventional neurofibromas in that the Meissner bodies showed prominent differentiation within the tumor. Further, the lamellar structures of the Meissner bodies reacted with S-100 protein, NSE, and vimentin antibodies, which are well-establishedimmunohistochemical markers of Schwann cells [6]. The results presented here are similar to those from previous reports investigating immunohistochemical characteristics of Meissner bodies [13-16]. In addition to the transition of neoplastic Schwann cells to Meissner bodies, as indicated by hematoxylin and eosin staining, the immunohistochemical findings suggest that aberrant differentiation of Schwann cells and the unusual proliferation of the Meissner bodies may be related to tumor growth.

Both histological and immunohistochemical findings of the present case mimic those of diffuse neurofibromas. In general, diffuse neurofibromas are closely associated with NF1 [1] and predominantly affect the skin. The lesions are characterized by an ill-defined, diffuse infiltrations of neurofibromatous collagen fibers into the reticular dermis and subcutaneous tissue. Diffuse neurofibromas are histopathologically composed of round or slightly fusiform Schwann cells that are uniformly 


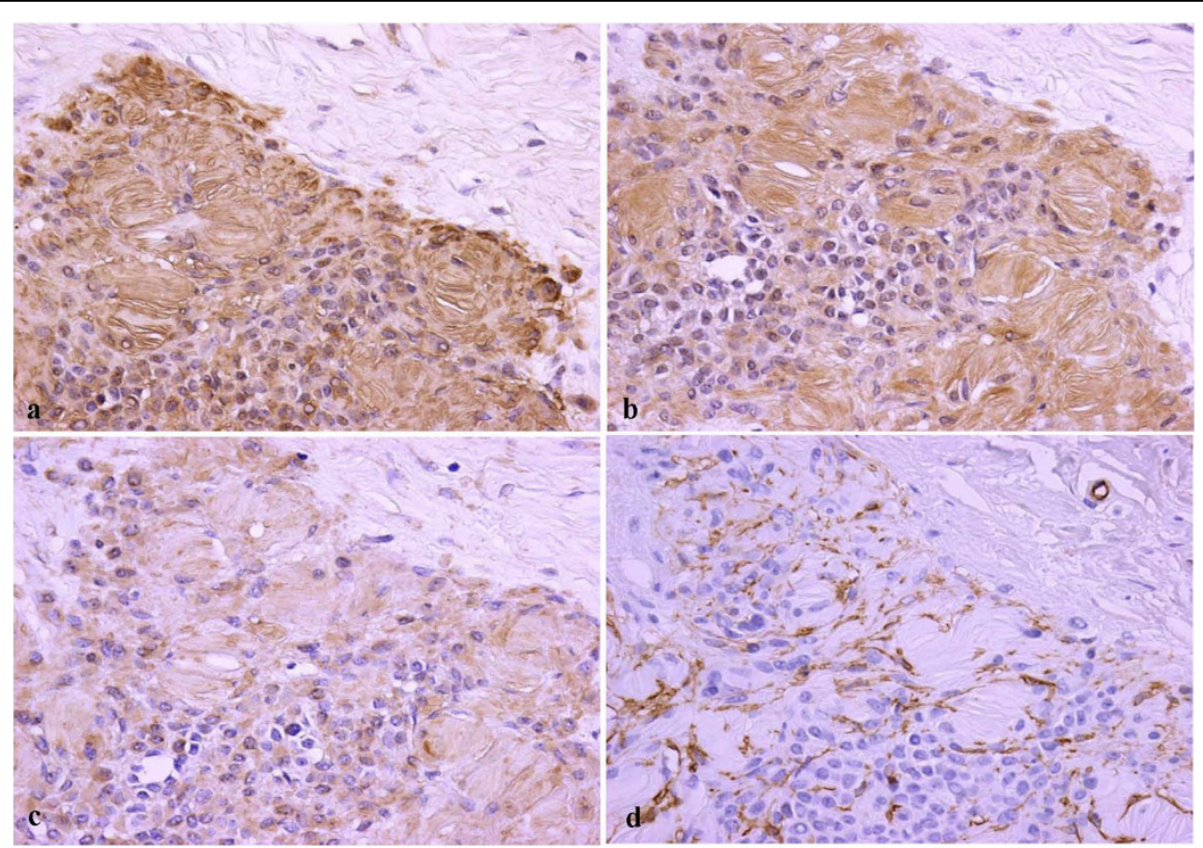

Figure 3 Immunoperoxidase staining of (a) S-100 protein, (b) NSE, (c) vimentin, and (d) CD34 in the oral neurofibroma. Lamellar structures in the Meissner bodies react intensely with anti-S-100 protein (a) and NSE (b) antibodies. Vimentin binds weakly to the Meissner bodies (c). Spindle cells around the Meissner bodies are stained with anti-CD34 antibody (d). (original magnification: a-d, $400 \times$ ).

distributed in a delicate collagenous background and are associated with sheets of laminated bodies resembling Meissner tactile corpuscles, as seen in the present case [1,17-21]. However, this case should not necessarily be diagnosed as a diffuse neurofibroma. The degree of infiltration of the tumor in the present case was difficult to measure because the gingiva is generally composed of a relatively small amount of mucosa without abundant adipose tissue and because the tumor was located on the surface of the alveolar bone. Wagner-Meissner



Figure 4 Infiltration of S-100 protein-positive Meissner bodies into the periosteal area of the tumor. Note the small clusters of Meissner bodies (arrow) and a nest of Schwann cells (arrow head) in the periosteal regions. (original magnification: $100 \times$ ) 
neurilemmoma could also be ruled out because of the absence of fibrous encapsulation and the presence of an abundant fibrous component in the tumor $[16,22]$.

The remaining immunohistochemical results presented in this report may aid in distinguishing the tumor from schwannomas. Chaubal et al reported the presence of CD34-positive spindle cells in neurofibromas but not in schwannomas [23]. Similarly, in the present case, CD34positive cells were found around the Meissner bodies in the tumor sheets. In addition, the tumor cells reacted negatively to calretinin antibody, which supports a recent report that suggested that positive calretinin antibody reaction occurred in almost all schwannomas but in only a small percentage of neurofibromas [24]. On the basis of the results, we infer that the present case is a unique variation of oral neurofibroma.

NF1-related neurofibromas are associated with somatic mutations at the NF1 gene, a tumor suppressor gene located in the pericentromeric region of chromosome 17 [1]. This gene codes for the protein neurofibromin, which regulates the ras-mediated cell growth pathway $[25,26]$. Recent studies have reported that mutations at the NF1 gene in Schwann cells are responsible for tumorigenesis of NF1-associated neurofibromas $[27,28]$. It has been suggested that the NF1 mutations produce abnormal neurofibromin, leading to increased levels of activating proteins (e.g., p21 $1^{\text {ras }}$ and p13) [29], which contribute to the cellular proliferation of Schwann cells associated with neurofibromas. A production of abnormal neurofibromin may also be related to the incidence of malignant peripheral nerve sheath tumor arising in neurofibromas [30]. In contrast, the pathogenesis of sporadic neurofibromas remains inadequately investigated. Using G-banding and fluorescence in situ hybridization analyses, Storlazzi et al demonstrated that somatic inactivation of the NF1 gene occurred through chromosomal translocations in sporadic neurofibromas, thereby suggesting the importance of NF1 inactivation in the tumorigenesis of sporadic neurofibromas [31]. This finding leads us to speculate that Schwann cells exhibiting an inactivated NF1 gene may lead to the development of a unique neurofibroma, as the one presented in this report.

\section{Conclusion}

An uncommon case of a sporadic, solitary oral neurofibroma with prominent Meissner bodies was identified. No formal description of a similar case was found in scientific literature. Both histological and immuno-histochemical findings in this case suggest that the aberrant differentiation of neoplastic Schwann cells may be implicated in Meissner body clusters, which are uncommon in a solitary neurofibroma.

\section{Consent}

Written informed consent was obtained from the patient for publication of this case report and accompanying images. A copy of the written consent is available for review by the Editor-in-Chief of Diagnostic Pathology.

\section{Authors' contributions}

JO performed the histological examination, analyzed the case, and prepared the manuscript. $\mathrm{Tl}$ and $\mathrm{RO}$ participated in the immunostaining. $\mathrm{KO}$ and $\mathrm{KT}$ participated in conducting pathological examinations. All authors have read and approved the final manuscript.

\section{Competing interests}

The authors declare that they have no competing interests.

Received: 28 July 2010 Accepted: 22 September 2010

Published: 22 September 2010

\section{References}

1. Weiss SW, Goldman JR: Neurofibroma. In Enzinger and Weiss's Soft tissue tumors. Edited by: Weiss SW, Goldman JR. St. Louis, London, Philadelphia, Sydney, Toronto: Mosby; , 4 2001:1122-1146.

2. Dickersin GR: The electron microscopic spectrum of nerve sheath tumors. Ultrastruct Pathol 1987, 11:103-146.

3. Erlandson RA, Woodruff JM: Peripheral nerve sheath tumors: an electron microscopic study of 43 cases. Cancer 1982, 49:273-287.

4. Peltonen J, Jaakkola S, Virtanen I, Pelliniemi L: Perineurial cells in culture. An immunocytochemical and electron microscopic study. Lab Invest 1987, 57:480-488.

5. MacDonald AW, Fletcher A: Expression of cytokeratin in the epithelium of dentigerous cysts and odontogenic keratocysts: an aid to diagnosis. J Clin Pathol 1989, 42:736-739.

6. Megahed M: Histopathological variants of neurofibroma. A study of 114 lesions. Am J Dermatopathol 1994, 16:486-495.

7. Shaktawat SS, Golka D: Floret-like multinucleated giant cells in neurofibroma. Diagn Pathol 2007, 2:47.

8. Zachariades N, Mezitis M, Vairaktaris E, Triantafyllou D, Skoura-Kafoussia C, Konsolaki-Agouridaki E, Hadjiolou E, Papavassiliou D: Benign neurogenic tumors of the oral cavity. Int J Oral Maxillofac Surg 1987, 16:70-76.

9. Richards D: Neurofibroma of the oral cavity. Br J Oral Surg 1983, 21:36-43.

10. Wright BA, Jackson D: Neural tumors of the oral cavity. A review of the spectrum of benign and malignant oral tumors of the oral cavity and jaws. Oral Surg Oral Med Oral Pathol 1980, 49:509-522.

11. Papadopoulos H, Zachariades N, Angelopoulos AP: Neurofibroma of the mandible. Review of the literature and report of a case. Int J Oral Surg 1981, 10:293-297.

12. Square CA, Johnson NW, Hopps RM: The connective tissue. In Human Oral Mucosa. Development, Structure and Function. Edited by: Square CA, Johnson NW, Hopps RM. Oxford, London, Edinburgh, Melbourne: Blackwell Scientific Publications; , 1 1976:45-66.

13. Watabe K, Kumanishi T, Ikuta F, Oyake Y: Tactile-like corpuscles in neurofibromas: immunohistochemical demonstration of S-100 protein. Acta Neuropathol (Berl) 1983, 61:173-177.

14. Morizumi H, Sano T, Hirose T, Hizawa K: Neurofibroma of the gallbladder seen as a papillary polyp. Acta Pathol Jpn 1988, 38:259-268.

15. Shiurba RA, Eng LF, Urich $H$ : The structure of pseudomeissnerian corpuscles. An immunohistochemical study. Acta Neuropathol 1984, 63:174-176.

16. Kaiserling E, Geerts ML: Tumour of Wagner-Meissner touch corpuscles. Wagner-Meissner neurilemmoma. Virchows Arch [Pathol Anat] 1986, 409:241-250.

17. Kapadia SB, Janecka IP, Curtin HD, Johnson BL: Diffuse neurofibroma of the orbit associated with temporal meningocele and neurofibromatosis1. Otolaryngol Head Neck Surg 1998, 119:652-655.

18. Coakley D, Atlas MD: Diffuse neurofibroma obstructing the external auditory meatus. J Laryngol Otol 1997, 111:145-147. 
19. de Varebeke SJ, de Schepper A, Hauben E, Declau F, van Marck E, van de Heyning PH: Subcutaneous diffuse neurofibroma of the neck: a case report. J Laryngol Otol 1996, 110:182-184.

20. Beggs I, Gilmour HM, Davie RM: Diffuse neurofibroma of the ankle. Clinic Radiol 1998, 53:755-759.

21. van Zuuren EJ, Posma AN: Diffuse neurofibroma on the lower back. J Am Acad Dermatol 2003, 48:938-940.

22. Ferrara N: Wagner-Meissner neurilemmoma of the vulva. Int I Dermatol 2003, 42:550-551.

23. Chaubal A, Paetau A, Zoltick P, Miettinen M: CD34 immunoreactivity in nervous system tumors. Acta Neuropathol 1994, 88:454-458.

24. Fine SW, McClain SA, Li M: Immunohistochemical staining for calretinin is useful for differentiating Schawannomas from neurofibromas. Am J Clin Pathol 2004, 122:552-559.

25. Viskochil D, Buchberg AM, Xu G, Cawthon RM, Stevens J, Wolff RK, Culver M, Carey JC, Copeland NG, Jenkins NA: Deletions and a translocation interrupt a cloned gene at the neurofibromatosis type 1 locus. Cell 1990, 62:187-192.

26. Wallace MR, Marchuk DA, Andersen LB, Letcher R, Odeh HM, Saulino AM, Fountain JW, Brereton A, Nicholson J, Mitchell AL: Type 1 neurofibromatosis gene: identification of a large transcript disrupted in three NF1 patients. Science 1990, 249:181-186.

27. Muir D, Neubauer D, Lim I, Yachnis AT, Wallace MR: Tumorigenic properties of neurofibromin-deficient neurofibroma Schwann cells. Am J Pathol 2001, 158:501-513.

28. Carroll SL, Ratner N: How does the Schwann cell lineage form tumors in NF1? Glia 2008, 56:1590-1605.

29. Hiatt K, Ingram DA, Huddleston H, Spandau DF, Kapur R, Clapp DW: Loss of the nf1 tumor suppressor gene decreases fas antigen expression in myeloid cells. Am J Pathol 2004, 164:1417-1479.

30. Kitamura M, Wada N, Nagata S, lizuka N, Jin YF, Tomoeda M, Yuki M, Naka N, Araki N, Yutani C, Tomita Y: Malignant peripheral nerve sheath tumor associated with neurofibromatosis type 1, with metastasis to the heart: a case report. Diagn Pathol 2010, 5:2.

31. Storlazzi $C T$, Von Steyern FV, Domanski HA, Mandahl N, Mertens F: Biallelic somatic inactivation of the NF1 gene through chromosomal translocations in a sporadic neurofibroma. Int J Cancer 2005, 117:1055-1057.

doi:10.1186/1746-1596-5-61

Cite this article as: Ohno et al: Solitary neurofibroma of the gingiva with prominent differentiation of Meissner bodies: a case report. Diagnostic Pathology 2010 5:61.

\section{Submit your next manuscript to BioMed Central and take full advantage of:}

- Convenient online submission

- Thorough peer review

- No space constraints or color figure charges

- Immediate publication on acceptance

- Inclusion in PubMed, CAS, Scopus and Google Scholar

- Research which is freely available for redistribution

Submit your manuscript at www.biomedcentral.com/submit
Ciomed Central 